\title{
TEORIZAÇÃO DA PRÁTICA OU PRÁTICA DA TEORIZAÇÃO? FORMAÇÃO DE PROFESSORES DE LÍNGUA INGLESA E ENSINO DE LÍNGUAS: reflexões sobre as vozes de um coletivo de trabalho
}

\section{THEORIZING ABOUT PRACTICE OR PRACTING BESIDES THEORIZING? UNDERGRADUATE DEGREE FOR TEACHERS OF ENGLISH AND LANGUAGE TEACHING: reflexions on a collective of work}

\begin{abstract}
Joelton Duarte de Santana ${ }^{33}$
RESUMO: O presente artigo analisa o papel da formação docente dos profissionais de língua inglesa a partir do ponto de vista do trabalhador em contexto de trabalho efetivo. A partir dos pressupostos teóricos da Clínica da Atividade, da Ergonomia da Atividade (AMIGUES, 2004; BUENO, 2007; 2009; FAITA, 2004) e do Interacionismo Sociodiscursivo (BRONCKART, 1999; 2008; MACHADO, 2007), o artigo em questão discute o papel da formação acadêmica do profissional de língua inglesa, bem como dos contextos e habilidades associados à ela, de modo a reunir reflexões sobre a formação desses profissionais a partir de suas vozes, que reunidas representam um coletivo de trabalho. Após a análise de um questionário empreendido com quatro professores de inglês, a saber, um de uma escola pública; um de um centro de idiomas; um de uma escola bilíngue; e um do curso de Letras-Inglês de uma instituição de ensino superior, foi possível observar que o processo de formação que dispuseram ofereceu pouco ou nenhum espaço dedicado à reflexão de seu trabalho e agir docentes, tampouco à ressignificação de suas práticas e (re)construção de suas autorrepresentações (DUARTE-DE-SANTANA, 2016) e identidades enquanto trabalhadores e profissionais de línguas, proporcionando-lhes, assim, muito mais uma teorização da prática do que uma prática a partir da teorização.
\end{abstract}

PALAVRAS-CHAVE: Formação docente. Professor de Inglês. Coletivo de Trabalho. Vozes.

\begin{abstract}
This paper analyzes the role played by the undergraduate degree provided to prospective teachers of English in tertiary education context. The analysis and discussion to be provided through this current paper happen to be through the viewpoint of teachers of English who are experiencing their effective work and have been acting as such. Based on the Ergonomics of Activity, Clinic of Activity (AMIGUES, 2004; BUENO, 2007; 2009; FAITA) and Socio-Discursive Interactionism (BRONCKART, 1999; 2008; MACHADO, 2007) theoretical frameworks, this paper also discusses about the role played by the undergraduate education provided to the aforementioned collective of work as well as the context and potential skills associated with it, therefore enabling us to gather evidences which may allow us to provide reflections on their undergraduate degree status since their voices have been heard. After analyzing four teachers of English, they who have been teaching English, respectively, at a public school, a language center (English course), a bilingual school and, ultimately, at an university in a Letters Undergraduate Degree Course, we could observe that opportunities and spaces to reflect on their effective work and practices were few or non-existent, as well as those provided to re-signify their teaching practices and their self-representations (DUARTE-DE-SANTANA, 2016) and identities, for they were more likely to be required to theorize about their prospective practice than practicing besides theorizing.
\end{abstract}

KEYWORDS: Undergraduate Education. Teacher of English. Collective of Work. Voices.

\footnotetext{
${ }^{33}$ Professor Colaborador do Programa de Pós-Graduação em Estudos da Linguagem (PPgEL) da Universidade Federal do Rio Grande do Norte (UFRN). Pós-doutorando em Estudos em Linguística Aplicada - Ensino e Aprendizagem de Línguas Estrangeiras também pelo Programa de Pós-Graduação em Estudos da Linguagem (PPgEL) da Universidade Federal do Rio Grande do Norte (UFRN). E-mail: duarte.joelton@gmail.com
} 


\section{Introdução}

A formação do professor, ao longo dos anos, tem sido alvo de interesse de muitos estudiosos e tema central da agenda dos estudos em Linguística Aplicada. O interesse pela formação docente dos profissionais da educação tem correspondido também à preocupação com a necessidade de incentivos que deem, inclusive, conta dos desafios impostos pelo sistema educacional dos tempos modernos.

Segundo Neto (2006), não apenas governos, mas, sobretudo, pesquisadores, gestores de sistemas e professores têm demonstrado crescente e notável interesse na formação de professores, assumindo-a, inclusive, como um elemento de políticas, pesquisas e avaliações educacionais.

No que diz respeito, especificamente, à formação dos profissionais da área de línguas, notadamente os de língua inglesa, objeto de estudo do presente artigo, apesar de todos os esforços e investimentos de instituições de ensino superior, bem como de programas, projetos e agências de fomento à pesquisa, tal formação tem sido ainda assumida ou alegadamente considerada como pouco eficiente e, de sobremodo, deficitária.

Os desafios do século XXI, ante à educação, têm imposto e buscado ressignificar não apenas as práticas e o perfil do profissional de língua inglesa, mas também as condições, contextos e fatores associados à sua formação acadêmica.

Nesta feita, objetivando refletir acerca do papel da formação acadêmica do profissional de língua inglesa, este quando já em situação de trabalho, bem como dos contextos e habilidades associados à ela, o presente artigo foi organizado em quatro capítulos, junto às seções de Introdução, Aspectos Metodológicos e Considerações Finais.

No capítulo intitulado: "formação de professores e prática docente", algumas considerações sobre a formação do professor de língua inglesa e sua prática docente são propostas de modo a refletir sobre o tempo e o espaço ofertados a esse profissional durante seu período formativo.

Em seguida, no capítulo de título: "o interacionismo sociodiscursivo enquanto perspectiva teórica para compreender a formação e o trabalho docentes", apresentamos os pressupostos teóricos do interacionismo sociodiscursivo relevantes à uma discussão sobre a formação e trabalho docentes.

Sobre o capítulo intitulado: "ciências do trabalho: ergonomia da atividade e clínica da atividade" importa mencionar que é proposta uma nova concepção de estudos em Linguística Aplicada sobre o trabalho e formação de professores.

Por fim, no capítulo de título: "professores de inglês e ensino de linguas: reflexões sobre as vozes de um coletivo de trabalho", propomos reflexões sobre as vozes de um coletivo de trabalho, analisando e contrastando as representações de profissionais de língua inglesa sobre sua formação docente, à medida que dissertam e refletem sobre o papel e a eficiência do seu processo formativo, uma vez já em situação de trabalho.

\section{Formação de professores e prática docente}

Os professores de língua inglesa têm sido formados, na contemporaneidade, para atuar em diversos contextos de ensino, quer sejam, sistema regular de ensino em redes públicas ou privadas, centro de idiomas, sistemas de ensino bilíngue e ensino superior em contexto universitário. Todavia, como já mencionado, a formação do professor de línguas tem sido entendida ou sugerida como deficitária ou problemática.

Barbosa (2010), em sua análise sobre formação docente, sugere que a aprendizagem indica, necessariamente, que alguém veio saber algo que não sabia, seja uma informação, um conceito, uma capacidade. No entanto, salienta o autor, que, nem 
sempre esse "algo novo" que se aprendeu transforma aquele que aprende em um novo "alguém”. Assim, para Barbosa (2010, p. 56), essa é uma característica forte do conceito de formação, o de que uma aprendizagem só é formativa à medida em que opera transformações na constituição daquele que aprende. É como se o conceito de formação indicasse a forma pela qual nossas aprendizagens e experiências nos constituem como um ser singular no mundo.

Neste sentido, acreditamos, ao propor o presente artigo, que a formação do professor de língua inglesa, deva constituir um tempo e um lugar de configuração profissional e da construção da identidade do ser professor e não apenas um pretenso espaço em que lhe são "conferidas" habilidades linguísticas ou didático-pedagógicas.

Assim, sugerimos que é preciso refletir não apenas sobre o estatuto e status da profissão do docente de língua inglesa, mas também de sua formação e como esses profissionais percebem o papel e os contributos desse processo formativo para o exercício do seu ofício, bem como de todo o seu coletivo de trabalho, uma vez já inseridos em situação de trabalho.

Segundo Assis (2010), nas últimas décadas, a formação e a atuação de professores têm sido objetos de pesquisas importantes que têm contribuído para o entendimento do ser e do fazer docente, e impactado, inclusive, na elaboração das novas diretrizes para a formação de professores.

Rafael (2001) sugere que a prática docente deve refletir à necessidade do domínio do conhecimento específico, como também de outros saberes e conteúdos, para atender as necessidades de situações diversas na sala de aula. Nesse sentido, o referido autor sugere que o professor precisa ser um adaptador, construindo e reconstruindo conceitos, que nem sempre são previstos pelas teorias abordadas na universidade, mas que se tornam objetos próprios da situação de ensino.

Se assim o for, caber-nos-iam os seguintes questionamentos: "Qual o papel da formação do professor de língua inglesa e quais conhecimentos tal formação deve(ria) conferi-lo? Resumir-se-ia sua formação ao conhecimento linguístico ou ao domínio de teorias de aprendizagem e métodos de ensino de línguas?

São reflexões dessa natureza, realizadas a partir de tais questionamentos e propostas a partir das vozes dos profissionais de língua inglesa, que o presente artigo visa a propor.

\section{O Interacionismo Sociodiscursivo enquanto perspectiva teórica para compreender a formação e o trabalho docentes}

- O Interacionismo Sociodiscursivo, ou ISD, como é mais comumente conhecido, encontra suas bases teóricas em várias áreas do conhecimento e, nesse sentido, não pode ceder aos "limites" dos estudos linguísticos, dos sociológicos, dos filosóficos ou dos psicológicos. Isto porque, o Interacionismo Sociodiscursivo situa-se em uma posição que é caracterizada como uma corrente da ciência do humano. Sobre essa questão, Bronckart (2008, p.237) esclarece que:

O que chamamos de interacionismo sociodiscursivo (ISD) é, inicialmente, uma posição epistemológica e uma tomada de posição sobre o desenvolvimento humano, sobre uma ciência do humano e sobre as condições de seu desenvolvimento. É uma posição que é, ao mesmo tempo, sócio-histórica, materialista-dialética e que considera importantes - eu diria que considera centrais - as questões da linguagem e da formação e educação. 
O trabalho do professor, nesse sentido, não se encontraria isolado, mas em uma rede múltipla de relações sociais existentes em um determinado contexto sócio-histórico, bem como inserido em um sistema de ensino e em um sistema educacional específico.

Machado (2007, p. 23) sugere que o trabalho docente consiste na mobilização pelo professor, de seu ser integral, em diferentes situações como planejamento de aula, de avaliação - com o objetivo de criar um meio que possibilite aos alunos a aprendizagem de um conjunto de conteúdos de sua disciplina e o desenvolvimento de capacidades específicas relacionadas a esse conteúdo, orientando-se por um projeto de ensino que lhe é prescrito por diferentes instâncias e com a utilização de instrumentos obtidos do meio social e na interação com diferentes outros que, de forma direta ou indireta, estão envolvidos na situação.

Nesta feita, tal contexto torna-se ideal para que seja proposta uma reflexão sobre o papel da formação do professor, permitindo-nos, assim, uma reflexão sobre o tempo e o espaço que são propostos ou ofertados a estes profissionais com vistas à sua mobilização integral e desenvolvimento de capacidades específicas junto ao seu ofício de professor e do seu coletivo de trabalho.

\section{Ciências do Trabalho: Ergonomia da Atividade e Clínica da Atividade}

Pesquisas recentes na área de Linguística Aplicada buscam investigar o trabalho do professor e sua formação a partir de uma nova concepção. Essa nova concepção tem sido influenciada por algumas Ciências do Trabalho.

Segundo Bueno (2007), nos últimos anos, tem surgido pesquisas que buscam situar o ensino como trabalho, que tem outros elementos além do próprio professor, seu saber e sua interação com os alunos, propondo-se a um estudo transdisciplinar, que considere os quadros e as tradições das Ciências do Trabalho, como, por exemplo, a Ergonomia da Atividade e a Clínica da Atividade.

Bueno (2009) afirma que a Ergonomia da Atividade e a Clínica da Atividade desenvolvem suas pesquisas observando o agir do trabalhador in loco, na própria situação do trabalho.

A Ergonomia da Atividade, nos termos de Faita (2004), trata do trabalho a partir do ponto de vista do trabalhador, fazendo uma análise que se centra no trabalho efetivo (os problemas "reais" em situações "reais", em tempo "real"), pressupondo que não se pode definir o trabalho efetivo sem se considerar aspectos que ligam o trabalhador à tarefa que ele é obrigado a cumprir.

Assim, a atividade do professor tem sido tomada como unidade de análise. Por atividade, entenda-se aquilo que, mentalmente, o sujeito realiza para executar uma determinada tarefa. Em decorrência disto, tal atividade só pode ser inferida a partir das ações realizadas por este sujeito (FAITA, 2004, p.39).

No que diz respeito ao ponto de vista do trabalhador e de seu coletivo de trabalho, interessa-nos saber qual o papel da formação docente dos professores de língua inglesa, os quais, em seu efetivo trabalho, lidam com problemas reais em situações reais e em tempo real. Destarte, em face de tais problemas, que possibilidades de solução a formação docente poderia ou deveria prever ou anteceder?

Por coletivo de trabalho, nos termos de Bueno (2009, p. 21), entenda-se tanto um grupo de pessoas como também a memória coletiva que cada profissional, nesse contexto professor, carrega em si, retomando-a a cada momento de seu trabalho.

Segundo Faita (2004, p. 64), os coletivos correspondem à mobilização coletiva do trabalhador mediante as prescrições dadas. Nas palavras do referido autor, coletivos seriam formas de fazer mais ou menos difundidas na profissão, que são, entretanto, formalizadas e transmitidas. 
Logo, o coletivo de trabalho tem papel bastante relevante no trabalho do professor, uma vez que permite a reorganização da tarefa, uma avaliação do trabalho, de sua formação, um apoio para as iniciativas, uma troca de saberes entre os professores e, principalmente, a construção de instrumentos para o trabalho.

Isto porque, no domínio do trabalho de ensino, segundo Amigues (2004), as dimensões constitutivas da atividade do professor compreenderiam o agir docente.

Nesse sentido, acreditamos que investigar as representações sobre a formação docente dos professores de língua inglesa, confrontá-las e discuti-las com os trabalhadores envolvidos, parece-nos ser fundamental para sua consolidação ou ressignificação.

\section{Aspectos metodológicos}

A pesquisa envolvendo a formação de professores, o agir e o fazer docentes tem cada vez mais exigido cuidado, por parte do pesquisador, durante o processo de análise de dados. Isto porque pesquisas desta natureza têm cada vez mais exigido que o pesquisador dispense tempo extensivo junto às informações obtidas através dos sujeitos investigados sem quaisquer emissões de juízo de valor mediante os discursos obtidos e as vozes reunidas.

Segundo Bronckart (1999), ao produzir um texto, o agente-produtor aciona um conjunto de representações inscritas em si pelos traços singulares e sociais que o constituem, nesse enlace, ele se constrói pelas relações que mantêm com o "outro" e com os "outros eus" que o moldam. Essas são, portanto, as vozes que assumem as formas mais concretas de realização do seu posicionamento e que, por isso, serão analisadas neste estudo.

Assim, importa mencionar que, isentando-se de quaisquer emissões de juízo de valor, tanto durante quanto após o seu empreendimento, um questionário contendo três (03) perguntas sobre o papel da formação docente e as características que levem os profissionais de língua inglesa, os quais já se encontram em situação de trabalho, a assumi-la como exitosa ou deficitária, foi respondido por quatro professores de língua inglesa cujas formações deramse em períodos diferentes.

O artigo em questão resulta de uma análise de corpus (CHIZZOTTI, 2008) realizada a partir do discurso de professores de língua inglesa do município de João Pessoa (PB) mediante o questionário que fora com eles empreendido. Foram utilizadas categorias de análise que encontram validade e relevância epistemológicas nas bases teóricas do Interacionismo Sociodiscursivo, como em Machado (2007) e Bronckart (1999; 2008), e na Ergonomia da Atividade e Clínica da Atividade, Bueno (2007; 2009), Faita (2004) e Amigues (2004), as quais não apenas apresentam pressupostos teóricos, mas, sobretudo, bases teórico-metodológicas para análise de produções que materializam e representam o trabalho, a formação e o agir docentes.

Importa mencionar que integraram o estudo do presente artigo um professor de inglês de uma escola pública - educação básica, cuja formação deu-se em 2010; um professor de língua inglesa de um centro de idiomas, que se formou em 2014; um professor de inglês de uma escola bilíngue da rede privada de ensino, cuja formação deu-se em 2016; e, por fim, um professor de língua inglesa do Curso de Letras-Inglês de uma instituição de ensino superior pública, cuja formação inicial (graduação) deu-se em 2005.

As respostas obtidas através do questionário proposto foram reunidas e são apresentadas na análise e discussão que constam na seção a seguir.

\section{Professores de inglês e ensino de línguas: reflexões sobre as vozes de um coletivo de trabalho}

Após anos de formação e, finalmente, sendo conferido o grau de licenciado em língua inglesa, professores iniciam o exercício do seu ofício em diferentes instituições de ensino e, 
enquanto trabalhadores, deparam-se com problemas "reais", em situações "reais" e em tempo "real", cujas especificidades e singularidades não foram, na maioria das vezes, previstas ou antecipadas durante seu processo formativo.

Assim, os excertos que serão propostos a seguir objetivam fazer ecoar o que esses profissionais têm a dizer sobre a formação que tiveram acesso durante seu período de graduação. Desse modo, formação e práticas docentes passam a ser discutidas e analisadas a partir do ponto de vista do trabalhador e de seu coletivo de trabalho.

Conforme mencionado, quatro professores de língua inglesa, cujas identidades foram preservadas, foram questionados sobre sua formação docente, a fim de que nos fosse oferecido um quadro ilustrativo sobre suas impressões, inquietações e posicionamentos sobre seu período de formação e os constantes desafios que lhe são impostos e aos quais são expostos durante o exercício do seu ofício.

O questionário proposto aos professores de língua inglesa mencionados tem início com a seguinte pergunta: "qual o papel/função de sua formação docente (graduação e, ou pósgraduação stricto ou lato senso) para e durante o exercício do seu ofício como professor de língua inglesa?", para a qual obtivemos as respostas que se seguem.

\begin{tabular}{|c|c|}
\hline $\begin{array}{c}\text { Professor de Inglês na } \\
\text { Educação Básica: Ensino } \\
\text { Regular }\end{array}$ & $\begin{array}{l}\text { Mediar o conhecimento da melhor forma, proporcionando ao aluno o acesso ao } \\
\text { ser, além da troca de experiências, que enriquece o aprendizado. }\end{array}$ \\
\hline $\begin{array}{c}\text { Professor de Inglês em } \\
\text { Escola Particular: } \\
\text { Programa Bilíngue }\end{array}$ & $\begin{array}{l}\text { Acredito que foi de fundamental importância em certos aspectos, porém no que } \\
\text { diz respeito ao dia-dia nem tanto. Na prática da profissão, foi possível perceber } \\
\text { que "dar aula" se aprende "dando aula". A teoria dos cursos é linda e ajuda, mas } \\
\text { não é tudo. }\end{array}$ \\
\hline $\begin{array}{l}\text { Professor de Inglês em } \\
\text { Centro de Idiomas }\end{array}$ & $\begin{array}{l}\text { Creio que a formação docente teve um papel muito mais de me ajudar a refletir } \\
\text { sobre aspectos teóricos envolvidos na sala de aula, que necessariamente ter um } \\
\text { papel preponderante no meu ofício como professor. Acho que o fato de eu ter } \\
\text { começado a dar aula muito cedo, fez com que eu pudesse desenvolver algumas } \\
\text { técnicas e habilidades de maneira mais abrangente e mais focada na sala de } \\
\text { aula. Isso porque durante a formação básica, os momentos de prática eram } \\
\text { muito escassos, somente aparecendo realmente durante as disciplinas de estágio } \\
\text { supervisionado, e mesmo assim de maneira reduzida, então o ofício mesmo foi } \\
\text { desenvolvido dentro de sala de aula, e antes que isso pudesse ser discutido } \\
\text { propriamente dito na faculdade. }\end{array}$ \\
\hline $\begin{array}{l}\text { Professor de Inglês em } \\
\text { Instituição de Ensino } \\
\text { Superior: Curso de } \\
\text { Letras }\end{array}$ & $\begin{array}{l}\text { Bom, como todo conhecimento é construído socialmente, no âmbito das } \\
\text { relações humanas, os anos de formação docente possibilita, então, um resultado } \\
\text { de um processo sócio histórico no qual os saberes linguísticos, filosóficos e } \\
\text { didáticos passam a ser considerados histórico e social. Nessa perspectiva, o } \\
\text { professor constrói sua formação, fortalece e enriquece seu aprendizado a partir } \\
\text { dos saberes científicos que são elencados no currículo, neste caso, do curso de } \\
\text { Licenciatura em Letras com habilitação em inglês. Em outras palavras, a } \\
\text { formação docente para meu ofício de professor de língua inglesa tem me } \\
\text { permitido construir socialmente os saberes necessários para o ensino deste } \\
\text { idioma no estabelecimento de ensino onde atuo como professor de língua } \\
\text { inglesa. }\end{array}$ \\
\hline
\end{tabular}

Quadro 01: Papel da formação para o profissional de língua inglesa. 
Conforme é possível perceber nas respostas propostas pelos professores em análise, embora o professor de inglês da educação básica do sistema de ensino da rede pública sugira, de forma bastante incipiente, que o papel de sua formação docente foi "mediar o conhecimento da melhor forma", "trocar experiências" e "enriquecer o aprendizado", tanto o professor de inglês do sistema de ensino bilíngue em escola particular, quanto o professor de inglês em curso de idiomas propõem que suas formações pouco ajudaram, no que diz respeito ao saber fazer do seu exercício, ou seja, ao seu agir e prática docentes, ao responderem, respectivamente que "dar aula se aprende dando aula" e que "os momentos de prática, na graduação, eram muito escassos".

Ao contrastar as respostas obtidas junto aos professores de língua inglesa, anteriormente mencionados, com a resposta do professor de inglês atuante em nível superior no curso de LetrasInglês, é por ele sugerido que "sua formação docente tem lhe permitido construir saberes necessários para o seu ofício de professor" e que "todo conhecimento é construído socialmente". Conforme é possível observar, o referido professor pontua os saberes "linguísticos, filosóficos e didáticos" como conhecimentos relevantes e indispensáveis para a "construção da formação, fortalecimento e enriquecimento do seu aprendizado como tal".

Todavia, as vozes que ecoam e nos convidam a refletir, a partir das respostas obtidas junto aos professores de inglês, que atuam em sistema de ensino bilíngue e centro de idiomas, respectivamente, são as de que: "a teoria dos cursos é linda e ajuda, mas não é tudo" e "a formação docente teve um papel muito mais de me ajudar a refletir sobre aspectos teóricos envolvidos na sala de aula, que necessariamente ter um papel preponderante no meu ofício como professor". Logo, os conhecimentos mencionados e apregoados pelo professor universitário de língua inglesa como indispensáveis, durante o processo formativo docente, sobretudo, os filosóficos, linguísticos e didáticos, têm sido, de alguma forma, negligenciado, ou atribuído pouca importância enquanto conhecimentos que deve(ria)m ser construídos social e historicamente.

Quando proposta a questão de número 02, na qual questionávamos: "na sua opinião, qual característica, aspecto ou fator tem sido negligenciado durante a formação do professor de língua inglesa? Qual(is) conhecimento(s) ou competência(s) a formação docente deste profissional deveria lhe conferir?", obtivemos as seguintes respostas.

\begin{tabular}{|c|l|}
\hline $\begin{array}{c}\text { Professor de Inglês na } \\
\text { Educação Básica: Ensino } \\
\text { Regular }\end{array}$ & $\begin{array}{l}\text { Eu acredito que seja uma formação capaz de atender tanto as necessidades } \\
\text { daquele profissional que tem fluência, quanto àqueles que ainda não possuem, } \\
\text { pois todos ali estão se capacitando para serem futuros formadores e muitas } \\
\text { vezes a universidade não dá esse suporte de como o docente deve mediar as } \\
\text { aulas de língua estrangeira, sejam elas voltadas para a conversação apenas, } \\
\text { sejam aquelas voltadas para o ensino de norma padrão. }\end{array}$ \\
\hline \multirow{2}{*}{$\begin{array}{c}\text { Profsor de Inglês em } \\
\text { Programa Particular: }\end{array}$} & $\begin{array}{l}\text { Balíngue } \\
\text { falar que a professora *********** está sendo ótima com relação a isso (paguei } \\
\text { uma cadeira de estágio com ela e foi ótimo). Outra coisa que eu senti falta e que } \\
\text { eu acredito que deva existir é que o professor deve ser ensinado a ensinar (não } \\
\text { consigo pensar em termo melhor) alunos com necessidades especificas, por } \\
\text { exemplo alunos que se encaixam no espectro autista ou alunos com TOD (acho } \\
\text { que é isso, transtorno opositor desafiador), ou alunos com TDA ou TDAH (não } \\
\text { me foi ensinado nada disso na faculdade e me fez muita falta). Precisamos ser } \\
\text { capazes de alcançar todos, nem que seja um pouquinho e não é fácil quando não } \\
\text { temos ideia do que pode nos esperar lá fora. Digo de novo, na teoria tudo é } \\
\text { lindo, os deuses da teoria teorizam, mas na vida real o professor que é o } \\
\text { milagreiro. A sala de aula é um universo e os professores uma poeira no meio } \\
\text { disso tudo tentando criar sentido no meio do caos. }\end{array}$ \\
\hline
\end{tabular}




\begin{tabular}{|c|l|}
\hline $\begin{array}{c}\text { Professor de Inglês em } \\
\text { Centro de Idiomas }\end{array}$ & $\begin{array}{l}\text { Vejo que a prática e reflexão em sala de aula são muito discutidos dentro da } \\
\text { faculdade, porém de maneira teórica. Fala-se muito sobre a necessidade de ser } \\
\text { um professor reflexivo, porém não há a oportunidade para os alunos fazerem } \\
\text { essa experiência de reflexão, isso porque atrelado a tal prática estaria a própria } \\
\text { prática de ensino, que como disse, é algo bem reduzido durante a formação } \\
\text { acadêmica inicial. }\end{array}$ \\
\hline $\begin{array}{c}\text { Professor de Inglês em } \\
\text { Instituição de Ensino }\end{array}$ & $\begin{array}{l}\text { A meu ver, as universidades que ofertam os cursos de Letras precisam priorizar } \\
\text { em sua formação o desenvolvimento da autonomia e reflexão crítica das } \\
\text { práticas docentes ao futuro licenciado em Letras que atuará como professor de } \\
\text { língua inglesa. O mercado impõe muitas exigências, tais como: a proliferação } \\
\text { dos cursos de línguas; a pressão imposta ao profissional de inglês por uma } \\
\text { certificação de proficiência; a oferta de materiais didáticos (boa parte comprada } \\
\text { em bancas de jornal e/ou revistas sem um profícuo estudo teórico) e dentre } \\
\text { outros. Isso tudo faz com que o professor de língua inglesa perca sua autonomia } \\
\text { e reflexão crítica, levando-o, assim, a "reproduzir" práticas ao invés de } \\
\text { "produzir" práticas que traduza um ensino e aprendizagem de modo histórico e } \\
\text { social. }\end{array}$ \\
\hline
\end{tabular}

Quadro 02: Conhecimentos negligenciados durante a formação docente.

Mais uma vez, é possível observar, a partir das respostas obtidas junto aos professores de língua inglesa atuantes, respectivamente, em uma escola de sistema bilíngue e de centro de idiomas, os quais sugerem "na minha época faltou prática (...). Eu acredito que o que deva existir é que o professor deve ser ensinado a ensinar, não consigo pensar em termo melhor" e "a prática e reflexão em sala de aula são muito discutidos dentro da faculdade, porém de maneira teórica. Fala-se muito sobre a necessidade de ser um professor reflexivo, porém não há a oportunidade para os alunos fazerem essa experiência de reflexão", que a formação do professor de língua inglesa, em alguma medida, tem preterido a prática da reflexão e da construção de autonomia desses profissionais, os quais alegam aprender a ensinar e exercer seu ofício, muito mais em contextos reais de ensino e em situações extremamente diversas em sala de aula, do que no espaço e contexto oferecidos durante sua formação docente.

Além das habilidades didático-pedagógicas e filosóficas interpretadas a partir das vozes dos professores anteriormente mencionados, como, por exemplo "saber ensinar" e "reflexão", convém mencionar que, segundo o professor de língua inglesa da rede pública, a habilidade linguística tem, igualmente, sido ignorada, ao sugerir que "(a) formação (docente deve ser) capaz de atender tanto as necessidades daquele profissional que tem fluência, quanto àqueles que ainda não possuem, pois todos ali estão se capacitando para serem futuros formadores e muitas vezes a universidade não dá esse suporte".

Por fim, a necessidade de promover uma formação reflexiva e que promova autonomia, por parte dos profissionais de língua inglesa, também é proposta pelo professor de língua inglesa do Curso de Letras Inglês, que afirma: "A meu ver, as universidades que ofertam os cursos de Letras precisam priorizar em sua formação o desenvolvimento da autonomia e reflexão crítica das práticas docentes ao futuro licenciado em Letras que atuará como professor de língua inglesa", salientando que as exigências impostas pelo mercado de trabalho fazem com que esse profissional perca sua autonomia e capacidade de reflexão crítica.

Desse modo, é possível perceber que o compromisso da formação docente do profissional de língua inglesa dev(eri)a recair tanto sobre as habilidades linguísticas, quanto as didático-pedagógicas, uma vez que, segundo depreendido das vozes dos profissionais entrevistados, falta compromisso com aqueles profissionais que não têm fluência, bem como, prática e reflexão sobre práticas e contextos de atuação futuros. 
Assim, baseando-nos nas representações propostas pelos professores de língua inglesa analisados, os contextos proporcionados pelos cursos de nível superior, de algum modo, ainda estariam negligenciando ou falhando na promoção e efetivação das habilidades supramencionadas, levando-nos a perceber que apesar dos diferentes períodos em que se deram suas formações, houve muito mais uma preocupação e compromisso com uma notável teorização sobre a prática docente do que uma provável ou potencial reflexão sobre a prática e trabalho docentes a partir dos espaços onde tais teorias foram propostas e aprendidas.

Por fim, temos a terceira e última questão proposta aos profissionais de língua inglesa sob análise, a pergunta de número 03, que indagava: "na sua opinião, quais as características que um professor de língua inglesa cuja formação docente foi considerada de excelência deve ter? E, o que falta em um professor que teve uma formação deficiente ou deficitária? Em outras palavras, de acordo com o seu ponto de vista, em que medida uma formação de um profissional de língua inglesa pode ou não ser considerada eficiente ou eficaz?”. Para a referida pergunta, obtivemos as respostas a seguir.

\begin{tabular}{|c|c|}
\hline $\begin{array}{c}\text { Professor de Inglês na } \\
\text { Educação Básica: Ensino } \\
\text { Regular }\end{array}$ & $\begin{array}{l}\text { É importante que um profissional, especialmente de língua estrangeira, } \\
\text { primeiramente apresente segurança naquilo que ele vai repassar. Ele não pode } \\
\text { se esquecer de que ele é um mediador do conhecimento e ele precisa estar } \\
\text { preparado para exercer tal papel; além disso, é importante ressaltar que, aliado a } \\
\text { este ponto, o professor precisa ser alguém em quem o aluno tenha a confiança } \\
\text { para chegar até ele. Por mais que alguns falem que o papel do professor é } \\
\text { apenas passar conhecimento e ponto final, quando o aluno constrói uma barreira } \\
\text { entre ele e o docente, dificilmente o processo de ensino/ aprendizagem será } \\
\text { efetivado. }\end{array}$ \\
\hline $\begin{array}{c}\text { Professor de Inglês em } \\
\text { Escola Particular: } \\
\text { Programa Bilíngue }\end{array}$ & $\begin{array}{l}\text { Ineficaz eu acredito que nenhuma formação seja, mas pra ser eficiente ao meu } \\
\text { ver, a formação tem que preparar o professor pra realidade, e não para as salas } \\
\text { de aulas ideais ou surrealistas que são teorizadas nos livros e textos acadêmicos. } \\
\text { O curso tem que preparar o futuro professor pra ter uma noção real do que } \\
\text { espera por ele, é muito ruim sair do curso achando que a prática é uma coisa e } \\
\text { na realidade ela é totalmente contrária. É triste. É ruim. É um sentimento } \\
\text { horrível entrar em sala de aula e pensar "nossa não sei o que fazer, não foi isso } \\
\text { que eu estudei" ou coisas semelhantes. Então uma formação de excelência é } \\
\text { aquela que vai preparar o professor o máximo possível pra sala de aula } \\
\text { verdadeira. Não estamos prontos para a surra que a sala de aula real nos dá } \\
\text { todos os dias, e isso deveria ser debatido no curso, estudado, levantado, passado } \\
\text { adiante. O curso tem que parar de criar ilusões! Me lembro como hoje que na } \\
\text { minha graduação foi feita uma pesquisa na cadeira de Pesquisa Aplicada e o } \\
\text { resultado foi terrível, } 40 \% \text { ( se não me engano) dos alunos de Letras eram } \\
\text { desmotivados com o curso e com a expectativa de futuro com relação a } \\
\text { profissão, muitos faziam letras e nem queriam ser professores. }\end{array}$ \\
\hline $\begin{array}{l}\text { Professor de Inglês em } \\
\text { Centro de Idiomas }\end{array}$ & $\begin{array}{l}\text { Um professor teria uma formação de excelência caso a faculdade pudesse } \\
\text { promover o desenvolvimento de habilidades linguísticas e pedagógicas de } \\
\text { maneira satisfatória. Por linguísticas, falo das habilidades de realmente ser } \\
\text { capaz de se expressar de maneira fluente e acurada na língua alvo. Em relação } \\
\text { às habilidades pedagógicas, falo sobre não apenas a ensinar o manejo de sala de } \\
\text { aula, através de práticas e reflexões sobre essas práticas, bem como ensinar a } \\
\text { lidar com dificuldades de aprendizagem e situações que superem expectativas, } \\
\text { para que o aluno possa se sentir motivado e consiga ter um desenvolvimento } \\
\text { condizente com o esperado para a idade ou nível de conhecimento. }\end{array}$ \\
\hline
\end{tabular}




\begin{tabular}{|c|l|}
\hline $\begin{array}{c}\text { Professor de Inglês em } \\
\text { Instituição de Ensino } \\
\text { Superior: Curso de } \\
\text { Letras }\end{array}$ & $\begin{array}{l}\text { Formação de excelência: demonstrar conhecimento dos fenômenos } \\
\text { educacionais, dos estudos linguísticos e domínio linguístico do idioma no qual } \\
\text { envolve a sua atividade docente. Estudar, discutir e implementar o } \\
\text { conhecimento teórico em sua prática docente, sem dúvida, faz do professor de } \\
\text { língua inglesa autônomo e crítico a ponto de buscar novas formas de ensinar o } \\
\text { idioma e, consequentemente, aprimorar seu domínio linguístico. } \\
\text { Formação deficitária: não demonstrar conhecimento dos estudos linguísticos. } \\
\text { Isso impossibilita o professor de inglês ter uma autonomia com relação aos } \\
\text { problemas educacionais que surgem ao longo do ensino do idioma. Isso, } \\
\text { portanto, atingirá sua formação proficiência no idioma também. }\end{array}$ \\
\hline
\end{tabular}

Quadro 03: Percepções dos professores sobre uma formação de excelência versus uma formação deficitária.

Ao serem questionados sobre o que julgam ser uma formação docente de excelência, todos os professores investigados, direta ou indiretamente, trazem à tona, mais uma vez, a necessidade de serem desenvolvidas, em contexto formativo, as habilidades didáticopedagógicas e linguísticas, ao sugerirem que: "ele (o profissional de língua inglesa) precisa estar preparado para exercer tal papel"; "pra ser eficiente ao meu ver, a formação tem que preparar o professor pra realidade, e não para as salas de aulas ideais ou surrealistas que são teorizadas nos livros e textos acadêmicos"; "um professor teria uma formação de excelência caso a faculdade pudesse promover o desenvolvimento de habilidades linguísticas e pedagógicas de maneira satisfatória"; "(uma formação de excelência deve) demonstrar conhecimento dos fenomenos educacionais, dos estudos linguísticos e domínio linguístico do idioma no qual envolve a sua atividade docente".

As vozes que se ouvem são de profissionais que, independentemente do contexto de atuação, sugerem que a formação que tiveram e o contexto formativo que experienciaram está longe de ser aqueles que descreveram e julgaram como pertencentes a de uma formação de excelência.

As vozes que se ouvem são de profissionais que alegam a necessidade de mais reflexão, de mais autonomia, de mais prática e de mais compromisso com as habilidades linguísticas associadas às didático-pedagógicas e vice-versa.

Ao sugerirem de modo extremamente explícito, professores de sistema de ensino bilíngue e de ensino superior do curso de Letras, que: "o curso tem que preparar o futuro professor pra ter uma noção real do que espera por ele (...).É triste. É ruim. É um sentimento horrivel entrar em sala de aula e pensar 'nossa não sei o que fazer, não foi isso que eu estudei' ou coisas semelhantes. (...) a formação de excelência é aquela que vai preparar o professor o máximo possível pra sala de aula verdadeira"; e que: "estudar, discutir e implementar o conhecimento teórico em sua prática docente, sem dúvida, faz do professor de língua inglesa autônomo e crítico", percebemos que muitos dos cursos de formação desses profissionais têm se comprometido muito mais com uma "teorização da prática do que com a prática a partir da teorização" e talvez seja esse o motivo, que, não apenas estudos em Linguística Aplicada venham considerando ou atribuindo, mas, sobretudo, o próprio coletivo de trabalho desses profissionais tenham nos oferecido indícios do porquê a formação de professores de língua inglesa seja, ainda, considerada como ineficiente, deficitária e longe de ser ideal.

\section{Algumas considerações}

Alguns estudos sobre formação e prática docentes, sobretudo do professor de língua inglesa, ao longo das décadas, têm, em maior ou menor grau, caracterizado-a como ineficiente 
e deficitária. Ao analisar e ouvir o professor de língua inglesa sobre o seu trabalho, estando em situação de trabalho, algumas considerações podem ser propostas.

Professores de língua inglesa têm alegado existir, durante seu processo formativo, pouco ou nenhum tempo e espaço dedicados à reflexão de seu trabalho e agir docentes, tampouco à ressignificação de suas práticas e (re)construção de suas autorrepresentações (DUARTE-DE-SANTANA, 2016) e identidades enquanto trabalhadores e profissionais de línguas, de modo a ser alcançada e efetivada a tão almejada e apregoada autonomia.

Almeida Filho (2013) sugere que os profissionais de língua inglesa devem se apropriar da ideia de que a graduação não é o ponto final na formação dos professores. No entanto, por mais evidente que tal assertiva possa ser ou soar, nos termos do referido autor, a graduação, como formação inicial, tem papel crucial e determinante para que seja possível o exercício de um ofício por parte de um profissional.

Portanto, faz-se necessário a existência de tempos e espaços, durante um processo formativo de professor de língua inglesa, que permitam a este profissional integrar às habilidades linguísticas, filosóficas e didático-pedagógicas que lhes são propostas, à prática da reflexão e do questionamento crítico, tão inerentes ao seu ofício quanto necessários ao seu processo formativo e ações profissionais futuras.

É na busca pela reflexão, pelo questionamento crítico e por uma formação prática que lhes confira autonomia e ressignifique suas identidades que os professores de língua inglesa serão transformados. Assim, e só assim, sua formação permitirá que se autorrepresente como agente transformador e membro ativo na sociedade do conhecimento.

Enquanto isto não ocorre, ou se ocorre, assim o faz a passos lentos, essas vozes e de todo o seu coletivo de trabalho continuarão a ecoar, obrigando-nos, cada vez que fizermos Linguística Aplicada, a refletir sobre a formação que a estes professores é ofertada e que resulta na memória coletiva que cada profissional carrega em si. Levando-nos, ainda e principalmente, a entender, bem como assumir posturas crítico-reflexivas mediante os porquês de tal formação ser ineficiente ou deficitária, ao invés de simplesmente continuar a caracterizá-la como tal.

\section{Referências}

ALMEIDA FILHO, J. C. P. Dimensões comunicativas no ensino de línguas. 7. ed. Campinas, SP: Pontes Editores, 2013.

AMIGUES, René. Trabalho do professor e trabalho de ensino. In: MACHADO, A. R (Org.). O Ensino como trabalho: uma abordagem discursiva. Ed. Londrina: Eduel, 2004. p. 35-54. ASSIS, J. A. Saberes, valores e crenças sobre a prática docente no discurso do professor em formação. Perspectiva, Florianópolis, v.28, n.2, p. 467-487, jul./dez, 2010.

BARBOSA, P. Orientações de formação e concepções de ambiente em cursos de formação continuada de professores de ciências do programa "Teia do Saber". 2010. 148 f. Dissertação (Mestrado em Ensino de Ciências) - Universidade de São Paulo, São Paulo, 2010.

BRONCKART, J. P. Atividade de linguagem, textos e discursos: por um interacionismo sociodiscursivo. Tradução de Anna Rachel Machado, Péricles Cunha. 2. ed. São Paulo: EDUC, 1999.

. O agir nos discursos: das concepções teóricas às concepções dos trabalhadores. Trad. Anna Raquel Machado, Maria de Lourdes Meirelles Matêncio. Campinas-SP: Mercado de Letras, 2008.

BUENO, Luzia. A construção de representações sobre o trabalho docente: o papel do estágio. 2007. 220 f. Tese (Doutorado em Linguística) - Pontifícia Universidade Católica de São Paulo, São Paulo, 2007. 
. O trabalho como uma forma de agir no ISD. In: BUENO, Luzia. A construção de representações sobre o trabalho docente: o papel do estágio. São Paulo: EDUC/Fapesp, 2009, caps. 2 e 3.

CHIZZOTTI, Antônio. Pesquisa qualitativa em ciências humanas e sociais. 2. ed. Petrópolis: Vozes, 2008.

DUARTE-DE-SANTANA, J. autorrepresentação do professor de língua inglesa e a elaboração de materiais didáticos: vozes sobre a atividade de um coletivo de trabalho. Revista Prolíngua, João Pessoa, v.10 n.3, p. 35-46, 2016.

FAITA, Daniel. Gêneros de discurso, gêneros de atividade, análise da atividade do professor. In: MACHADO, A. R. (Org.). O Ensino como trabalho - uma abordagem discursiva. Londrina: Eduel, 2004. p. 55-80.

MACHADO, A. R. Por uma concepção ampliada do trabalho do professor. In:

GUIMARÃES, Ana Maria de et. al. O interacionismo sociodiscursivo: questões epistemológicas e metodológicas. São Paulo: Mercado de Letras, 2007. p.77-97. NETO, José Batista. Formação de professores no contexto das reformas educacionais e do Estado. In: NETO, José Batista; SANTIAGO, Eliete. (Org.) Formação de professores e prática pedagógica. Recife: Fundação Joaquim Nabuco, Ed. Massangana, 2006. p. 89-100. RAFAEL, Edmilson Luiz. Atualização em sala de aula de saberes linguísticos de formação: os efeitos da transposição didática. In: KLEIMAN, Ângela B. (Org.) A formação do professor: perspectivas da linguística aplicada. Campinas: Mercado de Letras, 2001. p. 157180.

Submetido em 26/09/18

Aceito em 17/12/2018 